\title{
0 árbitro de futebol e a importância dos aspectos psicológicos: olhares da psicologia do esporte
}

\author{
The soccer referee and the importance of psychological aspects: \\ sport psychology looks
}

DOI: http://dx.doi.org/10.36453/2318-5104.2018.v16.n1.p269

\author{
Gabriel Petrini Rodrigues Cruz $^{1}$, Afonso Antonio Machado ${ }^{1}$, Ivan Wallan Tertuliano ${ }^{2}$, \\ Vivian de Oliveira ${ }^{3}$ \\ ${ }^{1}$ Universidade Estadual Paulista (UNESP/Rio Claro) \\ ${ }^{2}$ Centro Universitário Adventista de São Paulo (UNASP) \\ ${ }^{3}$ Centro Universitário FIEO - Fundação Instituto de Ensino para Osasco (UNIFIEO)
}

\begin{abstract}
RESUMO
Designados para impor e fazer valer as regras do jogo durante uma partida, os árbitros sofrem uma pressão vinda de todos os lados, pois diferente dos jogadores, um único erro pode lhe custar caro. Diante disso, o presente estudo objetiva organizar conteúdos acerca das habilidades psicológicas necessárias para o bom desempenho do árbitro de Futebol, propondo estratégias de melhoria das habilidades psicológicas junto aos árbitros de futebol. Assim, este estudo é caracterizado como um estudo bibliográfico de caráter descritivo-propositivo. Na organização de conteúdos, observou-se que a preparação psicológica deve fazer parte da preparação do mesmo, assim como a preparação física, ou seja, o árbitro deve estar bem fisicamente e psicologicamente, apresentando qualidades psicológicas que lhe ajudem a enfrentar toda a demanda psicológica negativa que uma partida de Futebol possa causar. Além disso, a preparação física contribuirá com o bom desempenho do árbitro, pois o mesmo poderá se posicionar adequadamente para observar o lance, diminuindo a dúvida sobre o ocorrido e, consequentemente, diminuindo a carga psicológica na tomada de decisão. Assim, conclui-se que as habilidades psicológicas, se trabalhadas de forma adequada, só favorecem o trabalho do árbitro de futebol, levando-o ao sucesso.
\end{abstract}

Palavras-chave: Futebol; Emoções; Arbitragem.

\section{ABSTRACT}

Designed to impose and lead athletes to comply with the rules of the game during a match, referees are pressured from all sides, because unlike players, a single mistake can be costly. Therefore, the present study aims to organize contents about the psychological skills necessary for the good performance of the Football referee, proposing strategies to improve the psychological skills of the football referees. Thus, this study is characterized as a descriptive-purpose bibliographic study. In the content organization, it was observed that the psychological preparation should be part of the preparation of the same, as well as the physical preparation, that is, the referee should be well physically and psychologically, presenting psychological qualities that help him to face all the negative psychological demands that a football match can cause. In addition, the physical preparation will contribute to the good performance of the referee, since he/she can position himself /herself adequately to observe the bid, reducing doubts about what has occurred and, consequently, reducing the psychological burden in decision making. Thus, it is concluded that psychological skills, if worked properly, only favor the work of the football referee, leading to success.

Keywords: Soccer; Emotions; Arbitration. 


\section{INTRODUÇÃO}

A partir do momento em que qualquer modalidade esportiva passa de um jogo lúdico para um jogo competitivo, com regras, é necessário uma pessoa que tenha conhecimento correto das regras para controlar a partida. No Futebol, diante do curto espaço de tempo para a tomada de decisões e a exposição a críticas e pressões de envolvidos na partida, tornando o ato de arbitrar uma tarefa muito complexa (GONZÁLEZ-OYA; DOSIL, 2007), é designado um trio de arbitragem, que sempre estarão sujeitos a ameaças e agressões físicas e verbais.

Pressionados e cobrados excessivamente pela perfeição, os árbitros de Futebol são designados a dirigir partidas que englobam muito mais que apenas um jogo com duas equipes adversárias. Organizadores, patrocinadores, dirigentes, mídia, torcedores, entre outros, fazem parte deste evento esportivo, e constantemente expressam duras críticas e opiniões contrárias às decisões tomadas pela arbitragem quando estas não lhes parecem agradáveis ou benéficas para a sua equipe (REIS, 2004). Exatamente por isso que De Rose Júnior, Pereira e Lemos (2002) afirmam que a arbitragem é um dos aspectos mais polêmicos envolvidos na competição esportiva, sendo frequentemente citada por atletas e dirigentes como responsáveis por seus insucessos e fonte de estresse, corroborando a literatura (JESUS et al., 2017; PEDROSA; GARCÍA-CUETO, 2015, 2016; ROLIM, 2014; SARMENTO; MARQUES; PEREIRA, 2015).

Em contrapartida, para Korte (2012), a polêmica em torno da arbitragem se dá pelo fato do árbitro ser o único responsável por todo o jogo, tornando o seu trabalho uma fonte de problemas. Diferente dos atletas, que quando cometem um erro, tem a responsabilidade diluída com os seus companheiros, o árbitro quando erra, sofre sozinho as consequências de seu erro. Dessa forma, a importância do trabalho da arbitragem é explicitada quando se analisa as consequências de seus atos, mais especificamente, de seus erros, pois uma decisão equivocada por parte dos mesmos pode alterar o resultado de um campeonato, interferindo diretamente no planejamento de equipes que investiram tempo e recursos financeiros na compra e preparação de seus atletas objetivando conquistas esportivas (BOSCHILIA; VLASTUIN, 2008; JESUS et al., 2017; MARCHI, 2008; ROLIM, 2014; SARMENTO; MARQUES; PEREIRA, 2015; SILVA; RODRIGUEZ-AÑEZ; FRÓMETA, 2002).

Para piorar a situação do árbitro, com o avanço de recursos tecnológicos que permitem, através de câmeras instaladas em diferentes ângulos dos estádios, análises minuciosas de lances e disputas imperceptíveis ao árbitro durante a partida, comprovam muitos erros de arbitragem, tornando o trabalho ainda mais árduo e difícil de ser executado (COSTA et al., 2010; SOUSA, 2016). Para que eles estejam prontos para desempenhar esta função, mesmo com todas estas adversidades citadas, os árbitros precisam estar preparados tecnicamente, fisicamente, e principalmente, psicologicamente, o que torna a função estressante devido à exigência de um bom fator emocional para se tomar decisões importantes em fração de segundos. Essa exigência pela perfeição da arbitragem gera um estresse grande nos árbitros, e quanto mais estressado estiver o árbitro, maior será a chance de errar (COSTA et al., 2010; OLIVEIRA et al., 2013).

Segundo Reis (2004) ao analisar as razões dos erros dos árbitros, a partir de observações baseadas nas análises dos jogos, observa-se que durante o jogo os árbitros ficam tensos e ansiosos, o que contribui com os erros de apontamento. Em contribuição para o nervosismo do árbitro encontra-se os jogadores, os treinadores, as torcidas, as ofensas que o árbitro recebe durante a partida e a necessidade de tomar inúmeras decisões rápidas, tudo isso em apenas duas horas, geram um grande desgaste emocional ao árbitro, sem contar a pressão para treinar e se preparar para desempenhar sua função, com a necessidade de manter outro tipo de trabalho para o sustento familiar, havendo a necessidade de um profissional da área da psicologia para trabalhar seu emocional (COSTA et al., 2010; OLIVEIRA et al.; 2013; PEDROSA; GARCÍA-CUETO, 2016; SAMULSKI; SILVA, 2009; SARMENTO; MARQUES; PEREIRA, 2015; SILVA et al., 2010).

Para Rech, Daronco e Paim (2002), existe uma forte relação entre as capacidades psicológicas dos árbitros e o desempenho dos mesmos, desse modo o sucesso do árbitro depende de suas capacidades mentais, autoconfiança, concentração e controle emocional. Cruz (1997) afirma que os árbitros, assim com os jogadores e treinadores são peças fundamentais em competições esportivas. A atuação deles na maioria dos esportes é o ponto chave para o espetáculo, mas para que tenham uma boa performance no campo de jogo, necessitam além do preparo técnico, uma boa preparação psicológica. 
Diante do exposto, o objetivo deste trabalho foi buscar evidências bibliográficas para a compreensão de que além do conhecimento técnico e preparo físico, é de suma importância uma preparação psicológica adequada para que os árbitros de futebol possam ter sucesso no exercício de sua função.

Sendo assim, o presente estudo objetiva apresentar um ponto de vista acerca das habilidades psicológicas necessárias para o bom desempenho do árbitro de futebol, propondo estratégias de melhoria das habilidades psicológicas junto aos árbitros de futebol, com os olhares da Psicologia do Esporte.

\section{ESTADO DA ARTE DA ARBITRAGEM NO FUTEBOL}

No Brasil, de acordo com Almeida (1974) e Martins e Paganella (2013), a figura do árbitro surgiu junto com o Futebol, o qual surgiu, no Brasil, em 1894, trazido da Inglaterra por Charles Miller. Com o passar dos anos, a regra relacionada à arbitragem foi sofrendo alterações, possibilitando um direito e poder maior aos árbitros, sustentando sua autoridade dentro de campo, pois o Futebol passou a ser praticado de forma competitiva, e não mais como lazer e diversão, envolvendo clubes de diversas regiões, estados e até países diferentes (MARTINS; PAGANELLA, 2013).

O árbitro de Futebol é a entidade oficial que regula o comportamento desportivo dos intervenientes diretos no jogo, fazendo cumprir as regras do jogo. Uma eficaz condução do jogo exige do árbitro uma boa percepção dos lances para uma correta tomada de decisões (REILLY, 1996). De acordo com a literatura (SILVA, 2004; OLIVEIRA et al., 2013) o árbitro está inserido em um ambiente que envolve tomada de decisões em curtos intervalos de tempo, exigindo eficiência e precisão. Sua tarefa é levar a partida até o final com competência, procurando não perder nenhum lance, mesmo que sua atuação esteja submetida a uma forte pressão (SARMENTO; MARQUES; PEREIRA, 2015). Para Rech, Daronco e Paim (2002) o papel da arbitragem deve estar direcionado para quatro responsabilidades principais: assegurar que o jogo decorra de acordo com suas regras, interferir o menos possível, estabelecer e manter uma boa atmosfera para o jogo e mostrar preocupação com os jogadores.

Diante do exposto, observa-se que as preparações físicas e técnicas são insuficientes para os árbitros alcançarem um desempenho satisfatório, pois precisam ter algumas habilidades psicológicas, como a autoconfiança, a concentração, o autocontrole emocional, a comunicação verbal e não verbal, e o bom relacionamento com os demais árbitros em campo para uma melhor atuação (GONZÁLEZ-OYA; DOSIL, 2004), fazendo-se necessária a aplicação da Psicologia do Esporte nestes membros essenciais do cenário dos esportes competitivos. Cruz (1997) ainda salienta que a maioria dos livros de árbitros consideram que para ser um bom árbitro é necessário apenas um bom entendimento das regras, boa forma física e bom posicionamento tático. Porém, há um grande número de árbitros que ressaltam a importância de boas condições psicológicas para uma melhor administração da partida, sendo um fator que diferencia um bom árbitro dos demais (JESUS et al., 2017; KARADEMIR, 2012; ROLIM, 2014;).

Falando-se do árbitro, diante de seu objetivo aplicado ao esporte de rendimento, torna-se essencial um trabalho psicológico adequado para a preparação do árbitro de Futebol, visando o seu sucesso, visto que a Psicologia do Esporte tem relação direta e fundamental com seu trabalho, tanto dentro como fora de campo (BRANDÃO, 2012; COSTA et al., 2010; FERREIRA; PEDROSA; GARCÍA-CUETO, 2015; 2016; SAMULSKI; SILVA, 2009).

Embora a preparação do árbitro seja de grande importância, de acordo com Silva, Rodriguez-Añez e Frómeta (2002), o mesmo passou por muito tempo despercebido nos estudos no esporte. Durante esse período as pesquisas no futebol se restringiam às regras, federações e jogadores. Todavia, estudos recentes têm buscado suprir a lacuna da literatura acerca da preparação psicológica do árbitro de futebol (AL-HALIQ; ALTAHAYNEH; OUDAT, 2014; COSTA et al., 2010; FERREIRA; BRANDÃO, 2012; GARCÍA-CUETO, 2015, 2016; KARADEMIR, 2012; OLIVEIRA et al., 2013; RABELO JÚNIOR, 2010; ROLIM, 2014; SARMENTO; MARQUES; PEREIRA, 2015; SOUSA, 2016; JESUS et al., 2017). Korte (2012) também lembra que dentro do universo esportivo, embora os estudos sobre arbitragem tenham aumentado de volume, os mesmos despertam pouco interesse por parte dos pesquisadores, comparados com outros elementos do cenário do futebol. GonzálesOya e Dosil (2004) salientam que, historicamente, a figura do árbitro é a que menos atenção tem recebido por 
parte dos psicólogos do esporte, entretanto, nota-se um aumento no número de trabalhos que conferem uma sessão especial para esse profissional, nos últimos 15 anos (CILLO, 2007; JESUS et al., 2017; OLIVEIRA et al., 2013; PEREIRA; SANTOS; SAMULSKI; SILVA, 2009;).

Apesar do aumento quantitativo e qualitativo das pesquisas sobre a preparação psicológica de árbitros, ainda sabe-se muito pouco, na prática, como prepará-los adequadamente para enfrentar os desafios de uma partida, da torcida em jogos importantes, da pressão imposta pela mídia esportiva, e até mesmo da pressão exercida dentro do campo por jogadores e treinadores, sem que isso interfira em seu desempenho e concentração (RABELO JÚNIOR, 2010). Samulski e Silva (2009) lembram a importância da preparação psicológica para o árbitro afirmando que a tomada de decisão dele pode vir a provocar um conflito, se não for aceita por uma das partes, e assim, pode trazer consequências pela carga de pressão psicológica da situação e pelos interesses que possam ter para cada grupo. Assim, devem estar preparados para enfrentar estes tipos de adversidades no campo de jogo.

Além dessas pressões psicológicas que sofrem na partida, também merecem destaque no contexto da arbitragem as condições em que atuam, a dificuldade em exercer sua função e as diversas emoções que têm durante o jogo, em apenas duas horas (COSTA et al., 2010; PEDROSA; GARCÍA-CUETO, 2015). Por isso, é fundamental o conhecimento das habilidades psicológicas que podem influenciar o seu comportamento durante uma partida, e como o árbitro pode desenvolvê-las em sua preparação para uma melhor atuação.

\section{A INFLUÊNCIA DO ESTRESSE NO RENDIMENTO DO ÁRBITRO}

Segundo Weinberg e Gould (2017), o estresse pode ser definido como um processo que ocorre quando o indivíduo percebe um desequilíbrio entre alguma demanda física ou psicológica e seus recursos para encarar a demanda em uma atividade considerada importante. Ele não é apenas um estímulo ou uma resposta, mas sim o processo pelo qual avaliamos e lidamos com as situações e desafios do ambiente.

O árbitro, na maioria das vezes, se encontra em estado de estresse e ameaça, já que sua função no esporte requer do mesmo uma interferência nas ações dos atletas realizadas durante a partida, objetivando aplicar as regras do esporte (COSTA et al., 2010). Segundo os mesmos autores, esta função de aplicar as regras e de decidir a favor ou contra uma equipe podem gerar situações de estresse e pressão em cima destes profissionais dentro e fora do campo.

Existem ainda, a elevada cobertura da mídia e o elevado número de interesses esportivos e financeiros envolvidos, que tornam o ambiente mais estressante para o árbitro e seus assistentes (GONZÁLEZ-OYA; DOSIL, 2007). A obrigação de não errar nas tomadas de decisão em lances da partida é uma das principais causas que podem gerar estresse nos árbitros, principalmente no que diz respeito ao controle das emoções mediante tomadas de decisão equivocadas provocadas por processos de falha humana (SILVA, 2004; LANE et al., 2006). O rótulo de profissão estressante segundo uma série de estudos apresentados por Zoller (1985) e corroborado por outros estudos (COSTA et al., 2010; JESUS et al., 2017; PEDROSA; GARCÍA-CUETO, 2015; RABELO JÚNIOR, 2010; ROLIM, 2014; SARMENTO; MARQUES; PEREIRA, 2015; SILVA et al., 2010) se dá pelos árbitros terem outras profissões, na maioria das vezes em período integral, por ter que apitar diversos jogos em uma semana, submetendo-se ao público e aos treinadores, além do cansaço e desgaste das viagens.

Corroborando os estudos acima, Samulski, Noce e Costa (1999) apontam os seguintes fatores como principais fontes de estresse para os árbitros de futebol: uma má preparação física, erros consecutivos em suas marcações, dormir mal na noite anterior ao jogo, cansaço físico e psicológico, além de chegar atrasados ao local da partida. Todos os estudos relacionados ao motivo do estresse na profissão árbitro de futebol apresentam evidências ou indícios de fatores considerados psicológicos, interferindo diretamente no desempenho dos mesmos (AL-HALIQ; ALTAHAYNEH; OUDAT, 2014; BRANDÃO; SERPA; WEINBERG, 2014; COSTA et al., 2010; KARADEMIR, 2012; PEDROSA; GARCÍA-CUETO, 2016). Portanto, o estresse além de fazer parte de qualquer esporte competitivo, é fundamental para o árbitro de futebol, principalmente quando irá atuar em grandes jogos ou competições importantes. Porém, o seu excesso, gerado por fatores negativos e acumulativos, como ambiente hostil, relações conturbadoras com jogadores e comissão técnica, torna-se prejudicial ao comportamento do árbitro. 


\section{O MEDO: INSEGURANÇA NO TRABALHO DE UM ÁRBITRO}

O medo é uma emoção que se caracteriza por um intenso sentimento habitualmente desagradável, provocado pela percepção de um perigo, seja ele presente ou futuro, real ou suposto (LAVOURA; MACHADO, 2008). O medo é uma das emoções primárias que resultam da aversão natural à ameaça, presente tanto nos animais como nos seres humanos (MACHADO; GOMES, 2011). De acordo com a literatura, o medo pode ser saudável, ou não, para saúde (WEINBERG; GOULD, 2017). O medo saudável pode ser entendido como aquele que é fundamental para a sobrevivência e adaptação do indivíduo ao ambiente (LAVOURA; MACHADO, 2008). Em contrapartida, o medo que não é saudável pode ser considerado como patológico, característico de fobias sociais, pânico, e que consequentemente atrapalham o funcionamento normal da vida do indivíduo (WEINBERG; GOULD, 2017).

Montiel (1998), ao refletir a paixão do jogo e o medo de errar, analisa que o bom árbitro não é aquele que comete menos erros, mas aquele em que o valor do seu trabalho compensa largamente os eventuais desacertos pontuais. Por entender que o medo de errar pode gerar insegurança, algumas reflexões efetuadas pelo autor vêm contribuir para o aprofundamento desta pesquisa. Segundo o mesmo, o medo está envolto num conjunto de fenômenos psicológicos mais abrangentes. A insegurança gera limitações de atitudes, de conhecimentos; gera indecisões, inibe a capacidade criativa, construtiva do indivíduo (GLEITMAN; REISBERG; GROSS, 2009; VOLI, 1998). Um mínimo de insegurança que um árbitro apresente é suficiente para desencadear na partida inúmeras dificuldades, como controle do jogo e dos jogadores, consequentemente, podendo causar nervosismo, apreensão, estresse e diversas dificuldades emocionais.

Um mínimo de insegurança na atuação do árbitro pode desencadear inúmeras dificuldades de "controle" do jogo, dos jogadores e, consequentemente, em si também desencadeiam descontroles, resistências, nervosismo, estresse, dificuldades de se aceitar e/ou aceitar mudanças (NUNES; SHIGUNOV, 2002). Através de outras capacidades psicológicas positivas, como confiança e motivação, o árbitro deve contornar a emoção medo dentro de campo, a fim de não titubear em suas marcações, procurando sempre fazer o que considera justo, demonstrando sempre segurança, pois se ele está ali, tem capacidade para comandar uma partida de futebol (COSTA et al., 2010; MACHADO, 2006; SAMULSKI; SILVA, 2009).

\section{ÁRBITRO E A ANSIEDADE DA FUNÇÃO}

Ansiedade é um estado emocional negativo caracterizado por nervosismo, preocupação e apreensão, associado com ativação ou agitação do corpo (WEINBERG; GOULD, 2017). É uma emoção que traz uma sensação de desconforto sempre que estamos em perigo. Dessa forma, esse sentimento nos prepara para enfrentar a situação e emitir comportamentos que reduzam ou previnam a ocorrência do perigo (GLEITMAN; REISBERG; GROSS, 2009). Ela pode se manifestar através de sintomas fisiológicos, sintomas cognitivos (nervosismo, apreensão, insegurança), e sintomas comportamentais.

$A$ ansiedade em excesso gera altos níveis de exaustão emocional, o que resulta em um desempenho pior (BOCK; FURTADO; TEIXEIRA, 2008; NASCIMENTO JUNIOR et al., 2016; WEINBERG; GOULD, 2017). Dosada de forma adequada, a ansiedade pode ajudar a alcançar o nível de ativação necessário para um desempenho ótimo, desde que controlada (NOGUEIRA et al., 2015). Muitos árbitros relatam uma grande ansiedade no começo das competições, que com o decorrer do campeonato é diminuída, chegando a um nível ótimo (SAMULSKI; SILVA, 2009; WEINBERG; GOULD, 2017).

É necessário também que o árbitro aceite os erros como uma oportunidade para aprender, diminuindo os padrões de exigência, pois a ansiedade se reduz a um nível administrável quando há diminuição dos padrões de exigência. Tendo em mente que a ansiedade é uma reação normal, e que se for aceita, permitirá que o indivíduo possa enfrentar as situações com mais facilidade. Outro fator que pode amenizar a ansiedade dos árbitros é uma qualidade na relação com outros árbitros, e com os dirigentes da comissão de arbitragem que fazem as escalas, que devem sempre oferecer apoio emocional para que os mesmos se sintam menos pressionados (MACHADO, 1997).

Em síntese, o nível de ansiedade do árbitro influencia como ele vê o jogo (WEINBERG; GOULD, 2017), ou 
seja, a ansiedade pode ser entendida como um estado emocional caracterizado por nervosismo, preocupação e agitação do corpo frente a uma situação incerta, neste caso, as situações decorrentes do jogo de futebol. Em outras palavras, a ansiedade, para psicologia esportiva, tem relação com situações futuras, na maioria das vezes, pois remete à incerteza de acontecimentos futuros, o que pode levar o árbitro a pensar sobre suas responsabilidades com o resultado final daquele evento (ROLIM, 2014).

\section{AUTOESTIMA COMO CONTRIBUIDOR DO ÁRBITRO}

Segundo Branden (2000), a capacidade autoestima, também chamada de confiança, pode ser definida como se fosse a nossa capacidade de pensar, a nossa habilidade de enfrentamento dos nossos desafios da própria vida. Ele ainda destaca como essência da autoestima a confiança nas próprias ideias e saber ser merecedor da felicidade. O mesmo autor ainda afirma que o nível da autoestima pode influenciar os atos assim como o modo de agir pode também influenciar o nível da autoestima, ou seja, uma correta tomada de decisão durante uma partida de futebol pode gerar um nível de autoestima favorável ao árbitro, ou então uma elevada autoestima, durante uma partida, poderá levá-lo a tomar decisões acertadas.

De acordo com Sousa (2016), a autoestima é uma aliada em suas atuações. De acordo com a autora, um grau elevado de autoestima é imprescindível para se atuar na arbitragem, especificamente, na arbitragem brasileira, devendo levar-se em consideração todas as situações de pressões e adversidades que um árbitro encontra em sua função (ROLIM, 2014).

Weinberg e Richardson (1990) reforçam esta ideia de que o bom árbitro necessita manter um nível elevado de autoconfiança para poder confiar na sua capacidade de realizar a tarefa de arbitrar e mesmo que erre, transmitirá esta segurança aos atletas e técnicos, fazendo com que todos o respeitem e às suas decisões também. Eles ainda destacam que o desempenho melhora à medida que o nível de confiança também melhora. Portanto, pode se garantir que possuir autoconfiança é indispensável para o árbitro alcançar seu potencial máximo (ROLIM, 2014).

Outra qualidade da autoestima/autoconfiança é o sentimento de segurança. Para Nunes e Shigunov (2002), a pessoa segura de suas possibilidades atreve-se a agir e, agindo, obtém resultados, mesmo que seja apenas uma aprendizagem para que o mesmo erro não se repita em outra ocasião. Eles ainda afirmam que os árbitros seguros acreditam neles próprios e nas suas capacidades para resolverem situações desafiantes, assim como a tomarem decisões perante situações com que se deparam nas partidas que atuam.

Sendo assim, torna-se de suma importância que o árbitro confie em sua capacidade de decisão para que possa obter êxito em sua atuação dentro de campo. Uma autoestima elevada possibilita ao árbitro alcançar patamares maiores em sua carreira, traçando desafios e metas mais exigentes, tendo mais persistência frente às dificuldades encontradas em suas partidas.

\section{ATENÇÃO COMO HABILIDADE PSICOLÓGICA IMPORTANTE NA ARBITRAGEM}

Segundo Helsen e Bultynck (2004), um árbitro de elite toma, em média, 137 decisões observáveis por jogo, em que resulta em torno de 3 a 4 por minuto. Isso torna a atenção uma importante variável para o sucesso da arbitragem. Para Brandão e Casal (2003), estar concentrado significa atentar aos estímulos relevantes das situações de jogo. Os desvios da atenção para sinais irrelevantes podem levar a erros de avaliação e, consequentemente, a erros de tomada de decisão.

A atenção é definida por Salazar, Rojas e Paz (2009) como um mecanismo interno, na qual o sujeito elabora e interpreta uma informação do ambiente, para organizá-la e dar-lhe sentido. A atenção é limitada, mas pode ser melhorada por meio da prática (SCHMIDT et al., 2016). Ainda, a arbitragem é uma atividade psicológica, que se baseia no processamento de informações para se emitir uma análise (marcação), em que a atenção tem papel fundamental (SALAZAR; ROJAS; PAZ, 2009). Já a concentração pode ser descrita como a capacidade de focalizar a atenção em um determinado objeto ou ação (SAMULSKI, 2002). No esporte a concentração é considerada como habilidade de focalizar a atenção em estímulos relevantes do ambiente e de mantê-la ao longo do evento esportivo (WEINBERG; GOULD, 2017). 
Manter o foco durante os noventa minutos de jogo pode ser um dos grandes desafios para a equipe de arbitragem, pois há diversos fatores, tanto internos como externos, que podem desviar a atenção dos mesmos (OLIVEIRA et al., 2013). Atitudes hostis do público, pressão de jogadores e técnicos, incomodação e fadiga muscular, eventos passados e futuros de seu cotidiano são alguns dos exemplos que podem gerar um déficit de atenção momentâneo nos árbitros, podendo comprometer a partida, sua atuação e até sua carreira dependendo da gravidade de seu erro (FERREIRA; BRANDÃO, 2012; OLIVEIRA et al., 2013; SOUSA, 2016).

A falta de aptidão física também pode exercer influência sobre a tomada de decisão, pois pode provocar confusão mental durante a execução de exercícios de alta intensidade, prejudicando a capacidade de julgamento (SILVA; FERNANDES; FERNANDEZ, 2011). A questão física é importante e está diretamente relacionada com os aspectos psicológicos. Friman, Nyberg e Norlander (2004) explicam, por exemplo, que quando o árbitro não corre no campo, ou seja, permanece distante dos locais das faltas no momento exato, os jogadores em campo costumam criticar. Desta forma, se o árbitro deixa de sinalizar penalidades importantes com frequência, os jogadores eventualmente perderão a confiança em seu trabalho e começarão a agir de forma agressiva e ameaçadora. Todo este cenário pode interferir no nível de atenção do árbitro durante a partida (OLIVEIRA et al., 2013).

Portanto, faz-se necessário que o árbitro tenha uma adequada forma física, um correto conhecimento e aplicação do regulamento (aspecto técnico), uma boa planificação das partidas (aspecto táctico), seja somado um bom nível de concentração mesmo depois de um erro cometido durante a partida, garantindo recursos psicológicos adequados para completar a partida com êxito (GONZÁLEZ-OYA; DOSIL, 2004; 2007)

\section{MOTIVAÇÃO PARA ATUAR COMO ÁRBITRO}

Segundo Samulski (2002), a motivação é caracterizada como um processo ativo, intencional e dirigido a uma meta, o qual depende da interação de fatores pessoais (intrínsecos) e ambientais (extrínsecos). Segundo esse modelo, a ativação apresenta uma determinante de motivação do comportamento (intenções, interesses, motivos e metas).

Voli (1998), afirma que um indivíduo com baixo nível de motivação mostra-se incapaz de alcançar alguns dos seus objetivos, ocorrendo uma grande dificuldade de tomar algumas decisões perante determinadas situações, não apresenta preocupações com a qualidade do trabalho, demonstra sentimento de inutilidade e falta de iniciativa. Entretanto, um indivíduo quando está motivado ele se sente disposto a buscar novas atividades, busca alternativas e soluções, e é capaz de usar a sua criatividade para desenvolver suas capacidades (WEINBERG; GOULD, 2017). Para Montiel (1998), a motivação para o árbitro de futebol pode ser classificada como intrínseca, representando o gosto e o prazer em arbitrar; ou extrínseca como o status perante a sociedade e o dinheiro.

Uma das maiores motivações dos árbitros é a paixão pelo futebol (COLLINA, 2004). De acordo com Vallerand et al. (2006), as pessoas apaixonadas pelo que fazem se sentem vivas, ou seja, apresentam maior disposição para participar da atividade e maior aceitação pessoal sobre tal atividade. Dessa forma, quando o árbitro está motivado com sua atuação, sente-se pertencente ao jogo e à tarefa, considerando-a parte de sua vida (BRANDÃO et al., 2011). Rolim (2014), em estudo com árbitros federados no Brasil, encontrou resultados que corroboram o exposto, ou seja, os resultados demonstraram o amor pelo futebol como razão principal para a iniciação na arbitragem, e para a permanência na atividade. Somado a esse resultado, o estudo de Rolim apresentou, também, não só a paixão pelo futebol como também a intenção de estar envolvido com o esporte e com alguma atividade física.

Em outro estudo (SLACK et al., 2013) com árbitros profissionais ingleses pode-se observar que a perspectiva de poderem progredir é uma importante força motivacional que caracteriza os bons árbitros. Porém, as dificuldades de progressão na carreira da arbitragem, as injustiças na avaliação de desempenho e a ausência de acompanhamento por parte dos dirigentes da arbitragem são outros dos aspectos que estes árbitros consideraram constrangedores para o desenvolvimento da atividade. Sobretudo os aspectos relacionados com às questões da avaliação de desempenho parecem ser merecedores de especial atenção, uma vez que mais de metade dos árbitros revelaram ter pensado abandonar a atividade, motivados por aquilo 
que consideram ser as injustiças nas avaliações (SARMENTO; MARQUES; PEREIRA, 2015). Voli (1998) relata também que a segurança, além de ser uma qualidade da autoestima, é também outro elemento motivacional, que estar seguro de si é sentir-se com liberdade de pensamento, de ação, de julgamento, de análise mais efetiva, diante de situações ou contextos.

Diante do exposto nesse tópico, pode se dizer que a motivação é importante para o árbitro atuar adequadamente em campo, esforçando-se ao máximo para não errar (BRANDÃO et al., 2011). Porém, a motivação para o árbitro se dá principalmente à chance de progressão na carreira, ou de alguém da comissão de arbitragem ver suas atuações, e assim evoluir em sua função, podendo ter a chance de um dia apitar jogos importantes e decisivos de campeonatos de grande expressão. Para isso, o árbitro deve confiar em sua comissão de arbitragem e seus dirigentes, que sempre estão trabalhando de forma interna para aprimorar cada vez mais a arbitragem de seu estado ou região.

\section{CONSIDERAÇÕES FINAIS}

Através da organização dos conteúdos, foi possível compreender a importância do preparo psicológico para que se possa executar a função árbitro de futebol com sucesso. Todavia, o presente estudo demonstra que a literatura carece de estudos que demonstrem como atuar na preparação psicológica do árbitro de futebol, com poucos estudos explorando tal variável (SOUSA, 2016). Além disso, observou-se que as habilidades psicológicas, se trabalhadas de forma correta, podem contribuir, de forma positiva, para o desempenho da arbitragem, que tem como missões fazer valer as regras de jogo, e controlar a partida (AL-HALIQ; ALTAHAYNEH; OUDAT, 2014; COSTA et al., 2010; FERREIRA; BRANDÃO, 2012; KARADEMIR, 2012; OLIVEIRA et al., 2013; PEDROSA; GARCÍACUETO, 2015, 2016; RABELO JÚNIOR, 2010; ROLIM, 2014; SARMENTO; MARQUES; PEREIRA, 2015).

É fato que a parte psicológica deve ser tratada com mais ênfase pelas federações ou empresas responsáveis pelos árbitros e suas escalas. No mínimo, o tratamento deve ser igual às partes técnicas e físicas dos mesmos, pois podemos analisar que a base do sucesso seria um equilibro entre estes pilares (SOUSA, 2016). Vale lembrar que o estado emocional do árbitro "caminha" junto com sua preparação física. $O$ árbitro sempre deve estar bem fisicamente para estar próximo do lance para julgar uma jogada da melhor maneira possível (SAMULSKI; SILVA, 2009; SOUSA, 2016).

Por fim, existe a necessidade de mais estudos relacionados aos árbitros de futebol, peças fundamentais para o espetáculo esportivo. Como já mencionado, os árbitros necessitam de uma preparação psicológica para desempenharem melhor sua função em campo, porém os estudos, até o presente momento, não apresentam modelos de preparação psicológica para os árbitros, o que reforça a necessidade de estudos acerca do tema.

\section{REFERÊNCIAS}

AL-HALIQ, M.; ALTAHAYNEH, Z. L.; OUDAT, M. Level of burnout amoung sports referees in Jordan. Journal of Physical Education and Sport, Pitesti, v. 14, n. 1, p. 47-51, 2014. .

ALMEIDA, K. Nosso futebol: o heroísmo, a glória e os ladrões. São Paulo: Arte e Texto, 1974.

BOCK, A. M. B.; FURTADO, O.; TEIXEIRA, M. L. T. Psicologias: uma introdução ao estudo de psicologia. São Paulo: Saraiva, 2008.

BOSCHILIA, B.; VLASTUIN, J.; MARCHI, J. R. W. Implicações da espetacularização do esporte na atuação dos árbitros de futebol. Revista Brasileira de Ciências do Esporte, Brasília, v. 30, n. 1, p. 57-73, 2008.

BRANDÃO, M. R. F.; CASAL, H. V. A psicologia do esporte. Santa Cruz do Sul: Cinergis, 2003.

BRANDÃO, M. R. F.; SERPA, S.; WEINBERG, R. Psychometric properties of the burnout inventory for referees. Motriz, Rio Claro, v. 20, n. 4, p. 374-83, 2014.

BRANDÃO, R.; SERPA, S.; KREBS, R.; ARAÚJO, D.; MACHADO, A. A. El significado de arbitrar: percepción de jueces de fútbol profesional. Revista de Psicologia del Deporte, Barcelona, v. 20, n. 2, p. 275-86, 2011.

BRANDEN, B. Auto-estima e os seus seis pilares. 5.ed. São Paulo: Saraiva, 2000. 
COLLINA, P. As minhas regras do jogo: o que o futebol me ensinou sobre a vida. Barcarena: Editorial Presença, 2004.

COSTA, V. T.; FERREIRA, R. M.; PENNA, E. M.; COSTA, I. T.; NOCE, F.; SIMIM, M. A. M. Análise estresse psíquico em árbitros de futebol. Revista Brasileira de Psicologia do Esporte, São Paulo, v. 3, n. 2, p. 2-16, 2010.

CRUZ, F. J. Asesoramiento psicológico en el arbitraje. In: CRUZ, F. J. (Ed.). Psicología del Deporte. 2.ed. Madrid: Editora Síntesis, 1997. p. 245-69.

DE ROSE JUNIOR, D.; PEREIRA, F. P.; LEMOS, R. F. Situações específicas de jogo causadores de "stress" em jogos oficiais de basquetebol. Revista Paulista de Educação Física, São Paulo, v. 16, n. 2, p. 16073, 2002.

FERREIRA, R. D.; BRANDÃO, M. R. F. Árbitro brasileiro de futebol profissional: percepção do significado do arbitrar. Revista da Educação Física/UEM, Maringá, v. 23, n. 2, p. 229-38, 2012.

FRIMAN, M.; NYBERG, C.; NORLANDER, T. Threats and aggression directed at soccer referees: An empirical phenomenological psychological study. The Qualitative Report, Fort Lauderdale, v. 9, p. $652-72,2004$.

GLEITMAN, H.; REISBERG, D.; GROSS, J. Psicologia. 7.ed. Porto Alegre: Artmed, 2009.

GONZÁLEZ-OYA, J.; DOSIL, J. Características psicológicas de árbitros de fútbol. Cuadernos de Psicología del Deporte, Murcia, v. 4, n. 1-2, p. 53-6, 2004.

GONZÁLEZ-OYA, J.; DOSIL, J. La psicología del árbitro de fútbol. La Coruña: Toxosoutos, 2007.

HELSEN, W.; BULTYNCK, J. B. Physical and perceptual-cognitive demands of top-class refereeing in association football. Journal of Sports Sciences, London, v. 22, p. 179-89, 2004.

JESUS, R. J.; MIRANDA, B. L. G.; SILVA, D. M. B.; CALDAS, E. S.; PESTANA, E. R.; ARAÚJO, M. L. Estudos sobre a visão dos árbitros em relação as suas atuações na categoria infantil, da modalidade futsal nos jogos escolares maranhenses, 2014. Revista Brasileira de Futsal e Futebol, São Paulo, v. 9, n. 35, p. 422-8, 2017.

KARADEMIR, T. The factors that influence the burn-out condition of city football referees. Journal of Physical Education and Sports Management, Nova lorque, v. 3, n. 2, p. 27-34, 2012.

KORTE, G. Treino mental: arbitragem no futebol. São Paulo: Annapurna, 2012.

LANE, A. M.; NEVILL, A. M.; AHMAD, N. S.; BALMER, N. Soccer referee decision-making: shall I blow the whistle? Journal of Sports Science and Medicine, Bursa, v. 5, p. 243-53, 2006.

LAVOURA, T. N.; MACHADO, A. A. Investigação do medo no contexto esportivo: necessidades do treinamento psicológico. Revista Brasileira de Psicologia do Esporte, São Paulo, v. 2, n. 1, p. 1-28, 2008.

MACHADO, A. A. Psicologia do esporte: temas emergentes. Jundaí: Ápice, 1997.

MACHADO, A. A. Psicologia do esporte: da educação física escolar ao esporte de alto nível. Rio de Janeiro: Guanabara Koogan, 2006.

MACHADO, A. A.; GOMES, R. Psicologia do esporte: da escola à competição. Várzea Paulista: Fontoura, 2011.

MARTINS, P. S.; PAGANELLA, M. A. Futebol e seus fundamentos. São Paulo: Ícone, 2013.

MONTIEL, A. A arbitragem e o futebol profissional. Lisboa: Horizonte, 1998.

NASCIMENTO JUNIOR, J. R. A.; BALBIM, G. M.; VISSOCI, J. R. N.; MOREIRA, C. R.; PASSOS, P. C. B.; VIEIRA, L. F. Análise das relações entre ansiedade estado e coesão de atletas de handebol. Revista Psicologia: Teoria e Prática, São Paulo, v. 18, n. 2, p. 89-102, 2016.

NOGUEIRA, F. C. A.; BARA FILHO, M. G.; LOURENÇO, L. M. Ansiedade competitiva e atletas de rendimento: uma revisão sistemática. In: II Congresso Internacional da Associação Latino-Americana de Ciências do Esporte, Juiz de Fora. Anais... Juiz de Fora: NGIME/UFJF, 2015.

NUNES, R.; SHIGUNOV, V. Auto-estima do árbitro de futebol profissional do estado de Santa Catarina. Revista da Educação Física/UEM, Maringá, v. 13, n. 2, p. 71-80, 2002.

OlIVEIRA, M. C.; SILVA, A. I.; AGRESTA, M. C.; BARROS NETO, T. L.; BRANDÃO, M. F. Nível de concentração e precisão de árbitros de futebol ao longo de uma partida. Motricidade, Covilhã, v. 9, n. 2, p. 13-22, 2013. 
PEDROSA, I.; GARCÍA-CUETO, E. Aspectos psicológicos en árbitros de élite: ¿afecta el salario a su bienestar emocional? Revista de Psicologia del Deporte, Barcelona, v. 24, n. 2, p. 241-8, 2015.

PEDROSA, I.; GARCÍA-CUETO, E. Síndrome de Burnout en árbitros de élite: la liga de fútbol profesional española (LFP) a estudio. Revista Iberoamericana de Diagnóstico y Evaluación Psicológica, Lisboa, v. 2, n. 42, p. 95-109, 2016.

PEREIRA, N. F.; SANTOS, R. G. M.; CILLO, E. N. P. Arbitragem no futebol de campo: estresse como produto de controle coercitivo. Revista Brasileira de Psicologia do Esporte, São Paulo, v. 1, n. 1, p. 2-10, 2007.

RABELO JÚNIOR, A. A. Análise das habilidades psicológicas dos árbitros da federação mineira de futebol. 2010. 40f. Monografia (Graduação em Educação Física) - Escola de Educação Física, Fisioterapia e Terapia Ocupacional, Universidade Federal de Minas Gerais, Belo Horizonte, 2010.

RECH, C. R.; DARONCO, A.; PAIM, M. C. C. Tipo de temperamento dos árbitros. Lecturas: Educación Física y Deportes, Revista Digital, Buenos Aires, v. 8, n. 48, 2002. Disponível em: <http://arquivo.ufv. br/des/futebol/artigos/Tipo\%20de\%20temperamento\%20dos\%20\%E1rbitros\%20de\%20futebol\%20 de\%20campo.pdf>. Acessado em: 04 de outubro de 2017.

REILLY, T. Science and soccer. London: E\&F.N. Spon, 1996.

REIS, V. Por que os árbitros erram tanto? Mas será os árbitros que erram? APAF (Associação Portuguesa de Árbitros de Futebol). Lisboa, 2004. Disponível em: <http://www.apaf.pt/caracter.

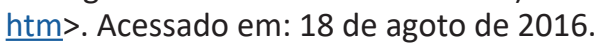

ROLIM, R. M. O escolher "ser" árbitro de futebol e a motivação para prática sob o olhar da psicologia do esporte: investigação centrada na tecnologia do GoogleTMDocs. 2014. 56f. Dissertação (Mestrado em Desenvolvimento Humano e Tecnologias) - Instituto de Biociências, Universidade Estadual Paulista, Rio Claro, 2014.

SALAZAR, M. C. R.; ROJAS, W. S.; PAZ, F. A. Juicio arbitral y desempeño cognoscitivo asociados con deshidratación en árbitros de fútbol. Revista Iberoamericana de Psicología del Ejercicio y el Deporte, Las Palmas de Gran Canaria, v. 4, n. 1, p. 29-44, 2009.

SAMULSKI, D. M. Psicologia do esporte. Barueri: Manole, 2002.

SAMULSKI, D. M.; NOCE, F.; COSTA, E. G. Análise do estresse psicológico do árbitro: um estudo comparativo entre futebol e voleibol. Revista da Associação dos Professoras de Educação Física de Londrina, Londrina, v. 14, n. 1, p. 13-28, 1999.

SAMULSKI, D. M.; SILVA, S. A. Psicologia aplicada à arbitragem. In: SAMULSKI, D. M. (Org.). Psicologia do esporte: conceitos e novas perspectivas. Barueri: Manole, 2009. p. 461-86.

SARMENTO, H. M.; MARQUES, A.; PEREIRA, A. Representações, estímulos e constrangimentos do árbitro de futebol de 11. Motriz, Rio Claro, v. 11, n. 4, p. 15-25, 2015.

SCHMIDT, R. A.; LEE, T. D.; SCHIMIDT, R. A.; LEE, T. D.; SCHMIDT, R. A.; LEE, T. D.; SCHIMIDT, R. A.; LEE, T. D. Aprendizagem e performance motora: dos princípios à aplicação. 5.ed. Porto Alegre: ArtMed, 2016.

SEVERINO, A. J. Metodologia do trabalho científico. 23.ed. São Paulo: Cortez, 2007.

SILVA, A. H.; COSTA, V. T.; FERREIRA, R. M.; MORAES, L. C. C. A.; SAMULSKI, D. M. Análise do estresse psíquico em árbitros de voleibol e basquetebol federados de Minas Gerais. Coleção Pesquisa em Educação Física, Várzea Paulista, v. 9, n. 2, p. 53-8, 2010.

SILVA, A. I.; FERNANDES, L. C.; FERNANDEZ, R. Time motion analysis of football (soccer) referees during official matches in relation to the type of fluid consumed. Brazilian Journal of Medical and Biological Research, Ribeirão Preto, v. 44, n. 8, p. 801-9, 2011.

SILVA, A. I.; RODRIGUEZ-AÑEZ, C. R.; FRÓMETA, E. R. O árbitro de futebol: uma abordagem históricocrítica. Revista da Educação Física/UEM, Maringá, v. 13, n. 1, p. 39-45, 2002.

SILVA, A. S. Construção e validação de um instrumento para medir o nível de estresse dos árbitros dos jogos esportivos coletivos. 2004. Dissertação (Mestrado em Educação Física) - Educação Física, Fisioterapia e Terapia Ocupacional, Universidade Federal de Minas Gerais, Belo Horizonte, 2004.

SLACK, L. A.; MAYNARD, I. W.; BUTT, J.; OLUSOGA, P. Factors underpinning football officiating excellence: perceptions of english premier league referees. Journal of Applied Sport Psychology, Cardiff, v. 25, n. 3, p. 298-315, 2013. 
SOUSA, M. A. M. Um olhar para os árbitros de futebol. Revista Brasileira de Psicologia do Esporte, São Paulo, v. 6, n. 1, p. 121-32, 2016.

VALLERAND, R. J.; ROUSSEAU, F. L.; GROUZET, F. M.; DUMAIS, A.; GRENIER, S.; BLANCHARD, C. M. Passion in sport: A look at determinants and affective experiences. Journal of Sport and Exercise Psychology, Birmingham, v. 28, n. 4, p. 454-78, 2006.

VOLI, F. A autoestima do professor. Madrid: Editorial y Distribuidora, 1998.

WEINBERG, R. S.; GOULD, D. Fundamentos da psicologia do esporte e do exercício. 6.ed. Porto Alegre: ArtMed, 2017.

WEINBERG, R. S.; RICHARDSON, P. Psychology of officiating. Champaign: Leisure Press, 1990.

ZOLLER, S. Learning how to live with stress. Referee Magazine, Racine, v. 10, n. 5, p. 51, 1985.

Autor correspondente: Ivan Wallan Tertuliano

E-mail: ivanwallan@gmail.com

Recebido em: 31 de outubro de 2017.

Aceito em: 09 de fevereiro de 2018. 